\title{
XXIII. An analysis of the magnetical pyrites; with remarks on some of the other sulphurets of iron
}

\section{Charles Hatchett Esq. F.R.S.}

To cite this article: Charles Hatchett Esq. F.R.S. (1805) XXIII. An analysis of the magnetical pyrites; with remarks on some of the other sulphurets of iron, Philosophical Magazine Series 1, 21:82, 133-147, DOI: $10.1080 / 14786440508676689$

To link to this article: http://dx.doi.org/10.1080/14786440508676689

曲 Published online: 18 May 2009.

Submit your article to this journal $\sqsubset \pi$

Џ Article views: 2

Q View related articles $\square$ 
* This conserquence of M. Peron," say the commissioners of the Institute, "appears to us the more probable, as it now proves the origin of those mountains of ice which in the polar regions have hitherto impeded the progress of the European navigators: it makes us readily comprehend how masses of ice, detached from the depths of the sea to float at the surface, can constitute in these regions projecting mountains of ice which simple congelation could never effect under that form."

This ingenious theory, therefore, of an interior central fire maintaining a uniform temperature of about 10 degrees throughout the whole mass, whether solid or liquid, of our globe, experiences at present the fate reserved, soon or late, for almost all human theorics. The calculations of Leibnitz, who first conceived it; the eloquence of Buffon, who decided his triumph, ought however, it would seem, to have secured to it a longer and more peaceable existence.

We shall terminate this extract with the opinion given on this subject by the commissioners of the Institute charged to give in a report upon it. "The memoir of M. Peron," say they, " seems to us to deserve great attention from philosophers: it is written with method, precision, and clearness. The experiments, of which the author gives an account, seem to have been made with that care and attention which are capable of ensuring the exactness of the results which they have furnished. We are therefore of opinion that this memoir deserves the approbation and even the praises of the class, and that it ought to be printed among those des Savans Etrangers. We will venture to add, that this is not the only claim of $M$. Peron to the gratitude of all those who are fond of the sciences; his labours during his voyage will considerably tend to enlarge the boundaries of the natural sciences."

XXIII. An Analysis of the magnetical Pyrites; with Remarks on some of the other Sulphurets of Iron. By Charles Hatchett, Esq. F.R.S.*

\section{$\S I$.}

Of the various metallic sulphurets which constitute one of the grand divisions of ores, none appear to be so universally dispersed throughout the globe as the sulphuret of

* From the Ticasations of tbe Royal Society of London for 1804 . 
iron, commonly called martial pyrites; for the species and varieties of this are found at all depths, and in all climates and soils, whether antient, or of alluvial and recent forma tion. It is remarkable also, that, under certain circumstances, this sulphuret is daily produced in the humid way: an instance of which, a few years back, I had the honour, in conjunction with Mr. Wiseman, to lay before this society:; and although, in regard to pecuniary value, the pyrites of iron may be considered as comparatively insignificant, yet there is every reason to believe, that in the operations of nature it is a substance of very considerable importance.

\section{$\S$ II.}

The species and varieties of martia! pyrites are in general so well known, and have been so frequently and accurately described, as to figure, lustre, colour, and other external characters, that it would be totally superfinous here to give any dctailed account of them. One of the species, however, merits peculiar notice, as possessing the remarkable property of strong magnetic polarity ; and, although it has been described by modern mineralogistst, it does not appear to have been as yet subjected to any regular chemical examination; so that, whether it be a suphuret of iron inherently endowed with the magnetical property, or a sulphuret in which particles of the ordinary magnetical iron ore are simply but minutely interspersed, has to this time remained undecided.

This species is known by the name of magnetical pyrites and is called by the Germans magnet-kies, or ferrum mineralisatum magnetico-pyritaceum.

It is most frequently of the colour of bronze, passing: to a pale cupreous red.

The lustre is metallic.

The fracture is unequal, and commonly coarse-grained, but sometimes imperfectly conchoidal.

The fragments are amorphous.

The trace is yellowish gray, with some metallic lustre.

It is not very hard; but, when struck with steel, sparks are produced, although with some difficulty.

It is brittle, and is easily broken.

This pyrites has been hitherto found only in some parts of Norway, Silesia, Bavaria, and especially at Geier, Mef-

* Transacticas of tbe Roval Saciety of London for $\mathbf{1} 79, \mathrm{~s}, 56 \%$

† Kuwan, vol. il. p. 79. Widenmanio, p. 792. Emmerling, ad edit tome iis p. $4 \hat{4} 6$, Karsten, p. 48. Brochant, tome is. p. $23 z$. 
fersdorf, and Breitenbrunn in Saxony ; but, having received some specimens from the right honourable Charles Greville, F.R.S., I was struck with their resemblance to the pyrites of Breitenbrunn, which happened at that time to be in my possession; and, upon trial, I found that they were magnctical, and agreed with the latter in every particular. Their magnetic power was such as strongly to affect a wellpoised needle of about three inches in length; a piece of the pyrites, nearly two inches square, acted upon the needle at the distance of four inches.

The powder (which is blackish gray, with but little metallic lustre) is immediatcly taken up by a common magnet; but the pyrites does not act thus on the powder, nor on iron filings, unless it has been placed for some time between magnetical bars; then, indeed, it acts powerfully, turns the needle completely round, attracts and takes up iron filings, and seems permancntly to retain this addition to its otigiual power.

In the specimens which I obtained, the north pole was generally the strongest.

This pyrites was found in Wales, about the year 1798, by the bononrable Robert Greville, F.R.S., who sent the specimens above described to his brother the right honourable Charles Greville, with the following account :

"It is found in great abundance in Caernarvonsbire, near the base of the mountain called Moel Elion, or probably with more accuracy Moel Elia, and opposite to the nountain ealled Mynydd Mawr. These mountains form the entrance into a little close valley, which leads to $\mathrm{Cy}$ ivellin lake, near Snowdon, a littic beyond the hamlet of Bettws.

"The vein appears to be some vards in depth and breadth, and seems to run from north to south, as it is found on Mynydd Mawr, which is across the narrow valley, and opposite to Mocl Wlia."

Mr. Robeir Gresille, in another part of his letter, states that copper ore has been worked in several of the adjacent places, and that, many years ago, captain Williams, of Glan yr Avon, employed sone miners at the place where. this pyrites is found, but the undertaking proved unproductive. Yellow copper ore is certainly in the vicinity; for some portions of it were adhering to the specimens which bave been mentioned; and I-shall here observe, that the stone which accompanies the magnetical pyrites is a variety of the lapis ollaris, or pot-stone, of a pale grayish green, containing smooth cubic crystals of common pyrites. 
$\S$ III.

From the appearance of those parts of the magnetical py rites which have been exposed to the weather, it seems ta be liable to oxidizement, but not to vitriolization.

The specific gravity, at temperature $65^{\circ}$ of Fahrenheit, is 4518 .

When exposed to the blowpipe, it emits a sulphureous o lour, and melts into a globule nearly black, which is attracted by the magnet.

500 grains, in coarse powder, were exposed, in a small earthen retort, to a red heat, during three hours. By this operation the weiglst of the powder was very little diminished; neither was there any appearance of sulphur in the receiver, which, however, smelt strongly of sulphureous acid.

300 grains of the same were put into a flat porcelain crucible, which was kept in a red heat, under a muffle, during four hours. The powder then appeared of a dark gray, with a tinge of deep red, and weighed 432.50 grains. The loss was therefore $67 \cdot 50=13.50$ per cent.; but, upon examining the residuum, I found that only part of the sulphur had been thus separated.

The magnetical pyrites, when digested in dilute sulphuric acid, is partially dissolved, with little effervescence, although there is a very perceptible odour of sulphuretted hydrogen.

The solution is of a very pale green colour.

Pure ammonia produced a dark green precipitate, tending to black ; and prussiate of potash formed a very pale blue precipitate, or rather a white precipitate mingled with a small portion of blue. The whole of the latter, however, by exposure to the air, gradually assumed the usual intensity of Prussian blne; and the blackish green precipitate, formed by ammonia, became gradually ochraceous. These effects, therefore, fully prove, that the iron in the solution was, for the greater part, at the ninimum of oxidizement, so as to form the grecn sulphate and white prussiate of iron *; and, consequently, that the iron of the magnetical pyrites is either quite, or very nearly, in the state of perfect metal.

This pyrites, when treated with nitric acid of the specific gravity of $1 \cdot 38$, diluted with an equal quantity of water, is at first but little affected; but, when heat is applied, it is dissolved with much effervescence, and discharge of nitrous gas : the effervescence, however, is by no means so violent

* Recbercbes strr le Bleu de Prusse, far M. Proust. Annaies de Cbimie, tome xxiil p. 8 : 
as when the common pyrites are treated in a similar manner. It is also worthy of notice, that if the digestion be not of too long duration, a considerable quantity of sulphur, ir. substance, is separated; whilst, on the contrary, scarcely any can be obtained from the common pyrites, when trea'fil in a similar manner; although $I$ shall soon have occasion to prove that the real quantity of sulphur is much nore considerable in the latter than in the former.

As soon as muriatic acid is poured on the powder of the magnetical pyrites a slight effer escence is produced, which becomes violently increased by the application of heat; a quantity of gas is discharged, which, by its odour, by its inflammability, by the colour of the flame, by the deposition of sulphur when burned, and by other properties, was proved to be sulphuretted hydrogen.

During the digestion sulphur was deposited, which so enveloped a small part of the pyrites as to protect it from the further action of the acid.

The solution was of a pale yellowish green colour. With prussiate of potash it afforled a pale blue precipitate, or rather a white precipitate mixed with blue; and with ammonia it formed a dark blackish-green precipitate, which gradually became ochraceous; so that these effects corroborated the conclusions which were founded on the properties of the sulphuric solntion, namely, that the iron contained in the pyrites is almost, if not quite, in the metallic state.

Other experiments were made; but, as they merely confirm the above observations, I shall proceed to give an account of the analysis.

\section{\$IV,}

\section{Analysis of the magnetical Pyrites,}

A. 100 grains, reduced to a fine powder, were digested, with two ounces of muriatic acid, in a glass matrass placed in a sand-bath. The effects already described took place, and a pale yellowish green solution was formed. The residuum was then again digested with two parts of muriatic acid mixed with one of nitric acid ; and a quantity of 'pure sulphur was obtained, which, being dried, weighed 14 grains.

B. The acid in which the residum had been digested was added to the first muriatic solution; some nitric acid was also poured in, to promote the oxidizement of the iron, and thcreby to facilitate the precipitation of it by ammonia, which 
was added after the liquor had been boiled for a considerable time. The precipitate thus obtained was boiled with lixivium of potash; it was then edulcorated, dried, made red-hot with wax in a covered porcelain crucible, was completely taken up by a magnet, and, being weighed, amounted to 80 grains.

C. The lixivium of potash was examined by muriate of ammonia, but no alumina was obtained.

D. To the filtrated liquor from which the iron had been precipitated by ammonia, muriate of barytes was added until it ceased to produce any precipitate: this was then digested with some very dilute muriatic acid; was collected, washed, and, after exposure to a low red heat for a few minutes in a crucible of platina, weighed 155 grains. If, therefore, the quantity of sulphur converted into sulphuric acid by the preceding operations, and precipitated by barytes, be calculated according to the accurate experiments of Mr. Chenevix, these 155 grains of sulphate of barytes will denote nearly 22.50 of sulphur; so that, with the addition of the 14 grains previously obtained in substance, the total quantity will amount to $36 \cdot 50$.

E. Moreover, from what has been stated it appears that the iron which was obtained in the form of black oxide weighed 80 grains; and, by adding these 80 grains to the 36.50 of suphun, an increase of weight is found $=16 \cdot 50$. This was evidently owing to the oxidizement of the iron, which, in the magnetical pyrites, exists quite, or very nearly, in the metallic state, but, by the operations of the analysis, had received this addition. The real quantity of iron must, on this account, be estimated at $63 \cdot 50$.

100 grains, therefore, of the magnetical pyrites yielded

$$
\begin{aligned}
& \text { Sulphur }\left\{\begin{array}{l}
\text { A. } 14 \\
\text { D. } 22.50
\end{array}\right\} 36.50 \text { grains. } \\
& \text { Iron }-\frac{63.50}{100^{\circ}}
\end{aligned}
$$

This analysis was repeated in a similar manner, excepting that the whole was digested in nitric acid until the sulphur was entirely converted into sulphuric acid. To the liquor which remained after the separation of the iron by ammonia, muriate of barytes was added, as before, and formed a precipitate which weighed 245 grains. Now, as the sulphuric acid in sulphate of barytes is estimated by Mr. Chenevix at 23:5 per cent, and the sulphur which is 
required to form the sulphuric acid contained in 100 parts of gulphate of barytes at $14 \cdot 5 *$, it follows, that 245 grains of dry sulphate of barytes contain sulphuric acid equal, vexy nearly, to 36 grains of sulphur; so that the two analyses corroborate each other. The proportion of sulphur in the magnetical pyrites may therefore be stated at $36^{\circ} 50$, or indeed at 37 per cent. if some small allowance be made for the occasional presence of earthy particles; a minute portion of quartz having been found, by the last analysis, after the complete acidification of the sulphur.

The inerease produced, by the operations of the analysis, in the wrisht of the iron, arose, as I have already remarked, from th: addition of oxygen; for the iron, as obtained by the analysis, was in the state of black oxide; but in this, and indeed in all pyrites, it undoubtedly exists very nearly, or quite, in the state of perfect metal. Now the black oxide of iron, called protoxide by Dr. Thomson $t$, has been proved by Lavoisier and Proust to consist of 100 parts of metallic iron combined with 37 of oxygen, thus forming 137 of black oxide: the exact proportion of oxygen is therefore 27 per cent., and 80 grains of this oxide must contain $21 \cdot 6$ of oxygen. But, in the above analyses of the magnetical pyrites, the increase of weight did not amount to more than 16.5 ; and we may therefore conclude that, in all probability, a quantity of oxygen $=5.1$ was previously combined with some part, or with the general mass, of the iron in the pyrites. A small part of the above-mentioned increase of weight must likewise have arisen from another cause; for, although the true proportions of the black oxide of iron are 27 of oxygen and 73 of iron, (so that 100 parts of the latter absorb 37 of the former, ) yet, in actual practice, it is difficult to obtain it exactly in this state, and there is commonly a small cxcess of weight: this I have repeatedly observed in many experiments, some of which were purposely made. When, for instance, 100 parts of fine iron wire were dissolved in muriatic acid, and afterwards precipitated by ammonia, edulcorated, dried, and made red-hot with a sinall quantity of wax in a covered porcelain crucible, the weight, instead of 137 , usually amounted to 139 or 140. The quantity of wax employed certainly did not afford a ponderable quantity of coal or other residuum; but the real cause of the increase of weight appears to be the air, which can scarcely be completely excluded, and which,

* Transactions of the Royal Irish Academy, vol. viii, p. 240.

$\dagger$ System of Chemistry, 3d edition, vol. i. p. 147 . 
after the wax is burned, combines with the superficial part of the oxide, and converts a portion of it into the red or peroxide; so that the surface in the crucible appears brown when compared with the interior.

To this cause, therefore, I am inclined also to attribute a small part of the increase observed in the weight of the iron obtained by the preceding analyses.

$$
\S \mathrm{V} \text {. }
$$

Before I make any observations on the nature of the sul phuret which has been proved to constitute the magnetical pyrites, it may be proper to state some comparative analyses which I have made of several of the common pyrites; and, as the method employed was precisely the same as that which has been described, all that seems to be requisite is to give an account of the results.

In each analysis the whole of the sulphur was converted into sulphuric acid, which was precipitated by barytes; and, in the selection of the specimens, great attention was paid to take the internal parts of the fragments, and not to make use of any which exhibited an appcarance of decomposition, or of extraneous substances.

The iron was, as before, reduced to the state of black oxide; and the addition of weight in each separate analysis corresponded, within a few fractional parts, with the proportion of oxygen requisite to form into black oxide a given quantity of metallic iron; equal to that which in each pyrites was ascertained to be the real proportion, by deducting the quantity of sulphur from the lotal quantity of each pyrites.

The iron, therefore, in these is completely metallic, and as such is stated in the following results.

No.1. Pyrites in the form of dodecaedrons Sulphur 52.15

with pentagonal faces. - $\quad$ Iron 47.85

Specific gravity 4830.

$100^{\circ}$

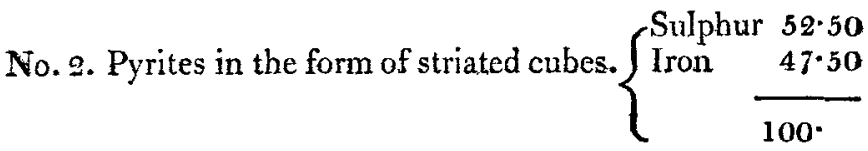

No. 3. Pyrites in the form of smooth po-7

lished cubes, found in the lapis ollaris Sulphur $52 \cdot 70$

which accompanies the magnetical Iron $47 \cdot 30$

pyrites.

Specifie gravity 4831 .

$100^{\circ}$

No.4. 
No. 4. Radiated pyrites.

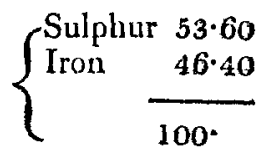

Specific gravity 4698 .

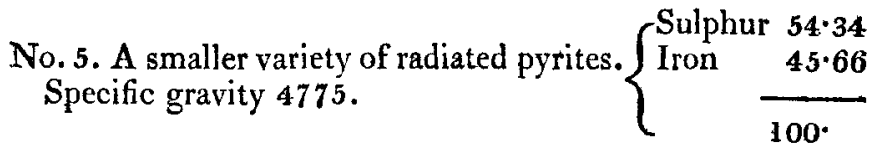

Considering the difference in the figure, lustre, and colour of these pyrites, I expected to bave found a much greater difference in the proportions of their component ingredients; but, as the results are the average of several experiments, I have not any reason to doubt their accuracy.

The pyrites crystallized in regular figures, sucb as cubes and dodecaedrons, according to the above analyses, contain less sulphur and more iron than the radiated pyrites, and perhaps than others which are not regularly crystallized. This difference, however, is not considerable ; for the dodecaedral pyrites, which afforded the smallest quantity of sulphur of any of the regularly crystallized pyrites, yielded $52 \cdot 15$; and the radiated pyrites, No. 5 , gave $54 \cdot 34$ : the difference, therefore, is only $2 \cdot 19$. So that the mean proportion of stlphur in all the pyrites which were examined is 53.24 per cent.; and, taking the proportion of sulphur in the magnetical pyrites at 36.50 or 37 , the difference between this and the mean of the common pyrites will be 16.74 or 16.24 . The magnetical pyrites, therefore, is quite distinct, as a sulphuret of iron, from the common martial pyrites; and in the following observations I shall prove that a sulphuret consisting of the proportions last mentioned has till now been unknown as a product of nature.

\section{$\S V I$.}

Although pyrites is one of the most common of mineral substances, yet the discovery of its real nature is comparatively of a late date; for it appears that even Agricola (whose knowledge of mineral bodies was certainly great, considering the state of science in his time) was not acquainted with its characteristic ingredient, namely, iron. According to Henckel, this was first noticed by our countryman Martin Lister, a member of this learned society, who says, " Pyrites purus putus ferri metallum est."

From the time of Henckel, pyrites seems little to have attracted the notice of chemists, until Mr. Proust, the 
learned professor of chemistry at Madrid, published two memoirs, in which he states that there are two stlphurets of iron, the one being artificial and the orher natural. The first is the sulphuret which is formed in laboratories, by adding sulphur to red-hot iron, or by exposing both of them to heat in a retort. This is distinguished from the second sulphuret (which is the conmon thartial pyrites) by its easy solubility in acids, especially in muriatic acid, by the formation of sulphuretted hydrogen gas during the solution of the sutphuret in the last-named acid, by its colour, and by its inferior density.

According to Mr. Proust, the first or artificial sulphuret is composed of 60 parts of sulphur, combinined with 100 parts of iron, 3 whilst the second strphicuret, or corhition py rites, consists of 90 parts of stlphuf athd 100 of iroti.

He moreover observes, that the sulphin of the first sit. phuret is difficaltly separated; but that the excess which is in the second sulphuret, or dommon pyrites, is easily expelled; turd is that portion which is obtaiffed by distillation, the residuum being then redtuced to the state of the first stilphuret *. 100 parts, therefbre, of this substatice, are comprosed of 69.50 of iron and $37^{\prime} 50$ of sulphur; 'affd 100 parts of enntires pyrites are, aceording to this statement, contiposed of $52 \cdot 04$ of iron and $47 \cdot 36$ of sklphuri:

These proportions Mr. Proust considers abthe winimution and maximum of the sulphurets of irom: For the latter he allowss some variation; bet the composition of the formet he regards as fixed by the invariable law of proportiknst; although he observes, that it has not as yet been discovered in the mineral kingdom $t$.

In support of these assertions Mr. Proust states

1. That the pyrites found near Soria, when dhstilled in a retont heated to redness, afforded nearly 20 per cent. of sulphur.

2. That the residuum of the above distillation had lost the external characters and chemical properties of pyrites, and had assumed those of the artificial sulphuret of irom.

* Fonral de Pbysique, tome liii. p. 89; and tome liv p. 8gi From pp. gr and 92 of tome liv. it is evideat that the author does not mean to assert that the first sulphuret contains 60 per cent. of sulphur; but that sor parts of iron are combined with 60 of sulphur, and form Ito of the sulohuret. In like manner, when 90 of sulphur are united with ros of iron, a su'stance andlogous to common pyrites is formed, whith weighs s 90 grains or parts.

+ Fournal de Pbysique, tome liii. p. 90 .

+ "'Lat regne minéral, jusqu'ici; ne uous a point encore presenté le fer sulfare au minumu. "-Fturnal de Physique, tome liv, $p .93$.

3: That 
3. That when to this residuum a quantity of sulphur was atded, and the whole was distilled in a degree of heat not too great, the 20 per cent. of sulphur, which had been separated by the first distillation, was by this again restored; and the mass in the retort thus recovered nearly the original colour, lustre, and chemical properties of the pyries.

4. That, by adding sulphur to iron filings, or fine iron wire, heated to a low red in a retart, a compound is obtained, in which the proportion of sulphur amounts anty to about 20 or 30 parts; but, if this compound is again treated with sulphur in a red heat, a sulphuret is formed, which is readily dissolved in acids, and plentifully afforts sulphuretted bydrogen gas.

This is the real minimum of the sulphurets of iron, fixed by the invariable law of proportions (according to $\mathbf{M r}$. Proust) at 59 or 60 of sulphur and 100 of iron, the formes being (as I have already observed) in the proportion of $37 \cdot 50$ per cent.

5. and lastly, That when this sulphuret is again mixed and distilled with sulphur, (due attention being paid: to the degree of heat,) the product is found to have assumed most of the chemical and external properties of the natural comman pyrites, density alone being excepted.

The application of the above observations to the principal subject of the present paper is sufficiently obvious; for; when it is considered that the magnetical pyrites is so dif: ferent from the common pyrites: in colour, hardness, solubility in sulphuric acid, and more especially in muriatic acid, with the copious production of sulphuretted hydrogen gas: when, by analysis, it has been found to consist of 36 or 37 of sulphur, combined with about 63 of metallic iron; and, when the artificial sulphuret of iron which has been lately described is proved to agree with the magnetical pyrites in the nature and proportions of its component ingredients, and in every one of the above-mentioned properties; it is evident that the maynetical pyrites is identically the same with this sulphuret, which hitherto has remained undiscovered in nalure, and has only been known as a product of our laboratories. In order, however, more fully to satisfy myself, I made experiments on the artificial sulphuret, which I formed with sulphur and fine iron wire.

This substance agreed, in all the properties which have been noticed, with the magnetical pyrites; and the precipitates obtained by adding prussiate of potash, and ammonia, to the muriatic and sulphuric solutions, were precisely si- 
milar. The specific gravity was 4390 , whilst (as I have already remarked) that of the magnetical pyrites is 4518 .

\section{\&II.}

So far, therefore, as can be proved by similarity in chemical properties and analysis, the magnetical pyrites is ind disputably a natural sulphuret, completely the same with that which till now has been only known as an artificial product; but, that the mind may be perfectly satisfied, another question must be solved, namely; How far do they accord in receiving and retaining the property of magnetism ? Common pyrites do not appear to affect the magnetic needle ; or, if some of them slightly act by attraction, (which, however, I never could perceive, nor recollect to have read in works expressly relating to magnetism, yet they do not possess, nor appear capable of acquiring, any magnetic polarity. As, therefore, the iron of pyrites is undoubtedly in the metallic state, and in a considerable proportion, the destruction of this characteristic property of metallio iron must be ascribed to the other ingredientsulphur.

But we have lately seen, that a natural combination of iron with 36.50 or 37 per cent. of sulphur, is in possession of all the properties supposed hitherto to appertain (in any marked degree) almost exclusively to the well known magnetic iron ore; and that the combination alluded to is strictly chemical, and not (as at first might have been imagined) a mixture of particles of magnetic iron ore with common pyrites *.

This is certainly very remarkable; and it induced me to examine the effects produced by sulphur on the capacity of metallic iron for receiving and retaining the maynetic properties. I therefore prepared some sulphuret of iron by adding a large quantity of sulphur to fiue iron wire in a moderate red heat.

The internal colour and lustre of the product were not very unlike those of the magnetical pyrites; and, after the mass bad been placed during a few hours between magnetical bars, I found that it possessed so strong a degree of polarity as to attract or repel the needle completely round upon its pivot; and, although several weeks have elapsed

* This has been sufficiently proved by the facts which have been srated; I shall however add, that upon digesting a mixture of the powder of common pyrites and iron flings in muriatic acid, I only obtained by drogen gas, exactly as if 1 had employed the iron filings without the pyrites. 
since it has been removed from the magnetical bars, it still retains its power with little diminution; like the marnetical pyrites, however, in its natural state, it is not sufficiently powerful to attract and take up iron filings.

But this sulphuret did not contain so much sulphur as the magnetical pyrites; I therefore mixed some of it, reduced to powder, with a large quantity of sulphur, and subjected it to distillation in a retort, which was at length heated until the intire bulb became red.

The sulphuret by this operation had assumed very much the appearance of the powder of common pyrites in respect to colour; but in its chemical properties, such as solubility in muriatic acid, with the production of sulphuretted hydrogen gas, as well as in the nature of the precipitates it afforded with prussiate of potash and with ammionia, it perfectly resembled the magnetical pyrites. Moreover, by analysis, it was found to consist of $\mathbf{3 5}$ parts of sulphur and 65 of iron; and although (being in a pulverulent state) its power; as to receiving and retaining the magnetic property, could not so easily be examined, yet, by being powerfully attracted hy the magnet, with some other circumstances, there was every reason to conclude that in this respect also it was not inferior.

Another portion of sulphuret was formed as above described; it was placed between magnetical bars, and, in like manner, received and retained the magnetic power.

It is certain, therefore, that when a quantity of sulphur equal to 35 or 37 per cent. is combined with iron; it not only does not prevent the iron from recciving the magnetic fluid, but enables it to retain it, so that the mass acts in every respect as a permanent magnet.

Black oxide of iron, by one operation, does not appear to combine with sulphur so readily as iron filings; a second operation, however, converts it into a sulphuret, very much resembling that which has just been described, including the chemical as well as the magnetical properties; but undoubtedly by these processes it is progressively converted; perfectly or very nearly, into the metallic state.

Iron combined with a larger proportion of oxygen, such as the fine gray specular iron from Sweden, will not form a sulphuret by the direct application of sulphur in one operation; although it becomes of a dark brown colour, partly iridescent, and is moderately attracted by a magnet.

50 grains of the magnetical pyrites, reduced to powder, and mixed with three times the weight of sulphur, were distilled in a retort until the bulb became moderately red-hot.

Vul. 21. No. 82. March 1805. K

After 
After the distillation the pyrites weighed 54.50 ; consequently, the addition of sulphur was 9 per cent., nuaking the total $=45 \cdot 50$ or 46 per cent. The powder was become. greenish yellow, very like that of the common pyrites: it did not alford any sulphuretted hydrogen when chigested irk muriatic acid; but it nevertheless was partially dissolved, and the solution, when examined by prussiate of potash, and by ammenia, was not different from that of the crude magnetical pyrites.

The powder which had bcen distilled with sulphur, and which had thus received an addition of 9 per cent. to its original quantity, was still capable of being completely taken up by a magnet.

From the whole of the experiments which hare been related, it is therefore evident; that iron, when combined with a considerable proportiou of sulphtrr, is not only still capable of receiving the niagnetic property, but is also thereby enabled to retain it, and thus, as I have already remarked, becomes a complete magnet; and it is not a little curious, that iron combined, as above stated, with 45 or 46 per cent. of sulphur, is capable of being taken up by a magnet, whilst iron combined with 52 per cent. or more of sulphur, (although likewise in the metallic state, does not sensibly affect the magnetic meedle; and hence, small as the difference may apprear, there is reason to conclude that the capacity of iron for magnetic action is destroyed by a certain proportion of sulphur, the effects of which, although little If at all sensible at 46 per cent., are yet nearly or quite absolute, in this destruction of magnetic influence, before it amounts to 32. But what the exact intermediate proportion of sulphur may be which is adequate to produce this effect, I have not as yet determined by actud experiment.

As carbon acts on soft iron, (which, although it most readily receives the magnetic influence, is unable to retain it so as to become a magnet without the addition of a certain praportion of carbort, by which it is rendered hard and brittle, or, in other worls, is converted into steel,) so, in like manner, does sulphur seem to act; for it has been proved, by the preceding experiments, that the brittle mass formed by the union of a certain proportion of this substance with iron, whether by nature or by art, becomes capable of retaining the magnetic virtue, and of acting as a complete magnet.

This remarkable coincidence in the effects produced on iron by carbon and sulphur, induced the to try the effects. of phosphorus; and my hope of success was increased by 
the remark of Mr. Pelletier, who says, that "the phosphuret of iron is attracted by the magnet *;" and therefore, although certain bodies may be thus attracted, without being capable of actually becoming permanent magnets, I was desirous to examine what might be the power, in this respect, of phosphuret of iron.

I therefore prepared a quantity of phosphuret of iron in the direct way, viz. by adding phosphorus, cut into small pieces, to fine iron wire made moderately red-hot in a crucible. The usual phænomena took place, such as the brilliant white flame, and the rapid melting of the iron, which, when cold, was white, with a striated grain, extremely brittle, hard, and completely converted into a phosphuret. The fragments of this were powerfully attracted by a magnet; and, after I had placed two or three of the largest pieces, during a few hours, between magnetical bars, I had the pleasure to find that these had become powerful magnets, which not only attracted or repelled the needle completely round, but were able to take up iron filings, and small pieces, about half an inch in length, of fine harpsichord wire; and, although they have now been removed from the magnetical bars more than three weeks, I cannot discover any diminution of the power which had thus been communicated to them.

The three inflammable substances, carbon, sulphur, and phosphorus, which, by their chemical effects on iron, in many respects resemble eâch other, have now thetefore been proved alike to possess the property of enabling iron to retain the power of magnetism : but 1 shall consider this more fully in the following section.

$$
\text { [lo be continued.] }
$$

XXIV. Olservations on the Change of some of the proximate Principles of Vegetables into Bitumen; with analytical Experiments on a peculiar Sulstance which is found with the Bovey Coal. By Charles Hatchetr, Esq. F.R.S. [Continued from page $5 x$.]

$$
\S \mathrm{V} \text {. }
$$

Dr. Milles, in his remarks on the Bovey coal, (which I have several times had occasion to notice in the course of this paper,) states, that "amongst the clay, but adhering

* "Le phesphure de fer est attirable a l'ainant." Annaiks de Cbime, tome xiii. p. i1 